ఠ

\title{
Non-small-cell lung cancer: molecular targeted therapy and personalized medicine - drug resistance, mechanisms, and strategies
}

This article was published in the following Dove Press journal:

Pharmacogenomics and Personalized Medicine

3 April 2013

Number of times this article has been viewed

\author{
Marybeth Sechler ${ }^{1,2}$ \\ Amber D Cizmic ${ }^{3}$ \\ Sreedevi Avasarala' \\ Michelle Van Scoyk' \\ Christine Brzezinski' \\ Nicole Kelley' \\ Rama Kamesh Bikkavilli' \\ Robert A Winn ${ }^{1-3}$ \\ 'Division of Pulmonary Sciences and \\ Critical Care, ${ }^{2}$ Program in Cancer \\ Biology, University of Colorado, \\ Aurora, CO, USA; ${ }^{3}$ Veterans Affairs \\ Medical Center, Denver, CO, USA
}

Correspondence: Robert A Winn Division of Pulmonary Sciences and Critical Care, School of Medicine, Anschutz Medical Campus, University of Colorado, Aurora, CO 80045, USA Tel +l 3037246095

Fax +I 303 72-6042

Email robert.winn@ucdenver.edu

\begin{abstract}
Targeted therapies for cancer bring the hope of specific treatment, providing high efficacy and in some cases lower toxicity than conventional treatment. Although targeted therapeutics have helped immensely in the treatment of several cancers, like chronic myelogenous leukemia, colon cancer, and breast cancer, the benefit of these agents in the treatment of lung cancer remains limited, in part due to the development of drug resistance. In this review, we discuss the mechanisms of drug resistance and the current strategies used to treat lung cancer. A better understanding of these drug-resistance mechanisms could potentially benefit from the development of a more robust personalized medicine approach for the treatment of lung cancer.
\end{abstract}

Keywords: lung cancer, drug targets, personalized medicine, NSCLC

\section{Introduction}

Lung cancer is the leading cause of cancer-related deaths in the US, with a mortality rate that is nearly twice as large as its closest follower in both men (prostate) and women (breast). ${ }^{1}$ Based on histology, lung cancers are classified into two major classes: small-cell lung cancer (SCLC), comprising 15\% of cases, and non-smallcell lung cancer (NSCLC), which comprise $85 \%$ of cases. While cigarette smokers constitute the main population at risk for developing lung cancer, the fastest-growing demographic currently is in nonsmoking women between the ages of 30 and $50 . .^{2,3}$ Unfortunately, due to the unavailability of early diagnostic tools, disease in two-thirds of these patients is not diagnosed until a later stage, leaving surgery as a nonviable course of action. Despite decades of research, the treatment options for lung cancer patients remain insufficient, either to provide a cure or even an appreciable survival benefit. The average 5-year survival rate has not improved greatly over the last 40 years, being cited currently at a mere $17 \%,{ }^{4}$ and highlighting the need for improved or novel therapeutic options.

The first major advancement in the treatment of lung cancer, however, came with the introduction of platinum-based chemotherapeutics, specifically cisplatin and carboplatin. The therapeutic use of platinum-based chemotherapies together with other agents such as gemcitabine, docetaxel, vinorelbine, and pemetrexed increased the 5-year survival rate from $5 \%$ to $14 \% .{ }^{5}$ However, even with various combinations of these drugs, it soon became clear that the usefulness of chemotherapy in the treatment of lung cancer had reached its limit. Despite this shortcoming, chemotherapy was still the best course of action until the approach to cancer treatment changed drastically with the observation of "oncogene addiction." This phenomenon describes when the 
loss of even a single mutated protein of which the cells have come to rely on can induce massive cell death and prevent disease progression. ${ }^{6}$ This new idea of targeting specific proteins opened the possibility of honing treatments, specific to the diseased cells, lessening the deleterious side effects of traditional treatments. This new therapeutic direction, initially championed with the development of imatinib, ${ }^{7}$ an Abelson murine leukemia viral oncogene homolog 1 kinase inhibitor, created a new frontier in the battle against many types of cancer. To date, a few of these targetable mutations have been identified in lung cancer. Some therapies designed to exploit these mutations have shown promise, both as single-line treatments and in combination with the standard platinum-based chemotherapies. In this context, receptor tyrosine kinase inhibitors (TKIs), which target epidermal growth factor receptor (EGFR) and anaplastic lymphoma kinase (ALK), have shown great promise in tailoring treatments to common kinase mutations found in NSCLC.

Unfortunately, despite the advances provided by these drugs, even the "addicted" cancers have a high incidence of relapse due to the development of resistance, limiting the "success" of these drugs in prolonging the median survival times by only a few months. Therefore, the need for focused research to identify new drugs and/or testing the existing drug combinations to mitigate drug-resistance mechanisms is critical to any future success in the field of lung cancer therapy. In this review, we highlight the current targeted therapies in use, as well as those under development for the treatment of NSCLC. In addition, we describe the mechanisms by which these therapies work, as well as why they also frequently fail.

\section{Current strategies used to treat lung cancer Receptor tyrosine kinase inhibitors in current clinical use \\ Epidermal growth-factor receptor}

EGFR is a receptor tyrosine kinase that is expressed in $60 \%$ of NSCLC. The binding of growth-factor ligands to EGFR initiates cell-signaling events activating the Phosphatidylinositide 3-kinase (PI3K)/Akt (involved in survival signaling) and the mitogen-activated protein kinases (MAPKs/ERK, involved in proliferation) pathways. ${ }^{8}$ The desire to inhibit the proliferative activity of EGFR in cancers led to the development of TKIs specific to EGFR. These TKIs function by binding to the adenosine triphosphate (ATP) pocket of the kinase, thereby preventing the receptor from activating its downstreamsignaling cascades. In the case of NSCLC, two such drugs gained US Food and Drug Administration approval in 2004: gefitinib ${ }^{9}$ and erlotinib. ${ }^{10}$ However, in trials performed just after being put on the market, gefitinib showed no survival advantage, showing a median survival of 5.6 months for gefitinib and 5.1 months on placebo (with a hazard ratio [HR] of 0.89$).{ }^{11}$ By comparison, erlotinib only improved median progression-free survival by 0.4 months compared to placebo $(\mathrm{HR}=0.61)$, and overall survival only improved by 2 months. ${ }^{12}$ In the following years, response to gefitinib was found to occur in only about $10 \%$ of cases in North American and European unselected populations (with slightly higher response rates in female Asian nonsmokers with adenocarcinoma), which corresponded with the presence of an activating mutation, but not with expression levels of EGFR. Thus far, the mutations correlating with TKI sensitivity are encoded within the tyrosine kinase domain of EGFR: in exons 18, 19, or 21, and often close to the ATP-binding pocket, gefitinib's target site. An extremely common mutation is on lysine 858 , which is usually mutated to either arginine (41\% of EGFR-activating mutations ${ }^{13}$ ), or more rarely to a methionine. Other identified mutations include the G719C substitution and several other deletion mutations, occurring between codons 746-750, 747-749, 747-751, 747-753, and 752-759, all of which were observed to be heterozygous. ${ }^{14-17}$ Erlotinib is believed to have similar efficacy to gefitinib, though this might be due to a lack of direct comparison in trials to highlight differences. ${ }^{18}$ Additionally, it has been shown that the type of mutation, in many cases, dictates the degree of sensitivity to treatment. ${ }^{19}$ Unfortunately, despite any initial response in slowing disease progression, patients with EGFR-mutant NSCLC will develop progression of disease on TKI therapy after 10-16 months, resulting in these drugs only improving the median survival time by several weeks. ${ }^{20-22}$ This is the major drawback with existing therapy, which has driven research to further explore the mechanisms of acquired resistance.

\section{Resistance to EGFR TKIs}

The molecular mechanisms in acquiring resistance to EGFR TKIs are numerous. Often a secondary mutation, substituting threonine with a methionine at position 790 results in an increased affinity for ATP. ${ }^{23}$ This increases competition for binding, rendering the drugs ineffective. ${ }^{24}$ This mutation is seen in about $50 \%$ of cases with acquired resistance. ${ }^{25,26}$ Several other similar mutations in the kinase domain have been shown to cause resistance, including D761Y, L747S, and T854A. ${ }^{27}$ Another mechanism is via the amplification of another receptor that signals to similar downstream mediators like that of EGFR. A fairly common example is the 
upregulation of Met, which can also activate the downstream $\mathrm{PI} 3 \mathrm{~K} / \mathrm{Akt}$ pathway without requiring EGFR. ${ }^{28-30}$ Along similar lines, the upregulation of the ligand hepatocyte growth factor can increase Met activity. While these mechanisms are common, a number of cases have been observed where resistance appears through alternative means. These include the downregulation of repressors, such as phosphatase and tensin homologue, or even activation of completely different pathways, such as turning on the nuclear factor kappa-lightchain enhancer of activated $\mathrm{B}$ cells transcription factor. ${ }^{27,31}$ An additional mechanism for the development of resistance is via the epithelial-mesenchymal transition (EMT). ${ }^{32}$ This describes alterations in a cell where it loses the adherencejunction protein E-cadherin, becomes more mesenchymal in morphology, and with increased motility. While EMT is a natural event during development, its aberrant occurrence makes it an important mediator of cell invasion and metastasis. Additionally, cells that have undergone EMT also show development of drug resistance to TKIs. ${ }^{32}$ Specifically, a more recent work has identified an E-cadherin repressor, Slug, as a critical mediator of EMT and as a mediator of resistance to gefitinib in NSCLC cell lines. ${ }^{33,34}$ Therefore, inhibition of Slug might as well represent a possible mechanism for resensitization of TKI resistant EGFR-mediated cancers.

While these mechanisms describe acquired resistance, cancer cells can also develop resistance to a drug without ever being exposed to it. Recently it has been observed that a polymorphism in BCL2-like 11, a proapoptotic protein, inhibits normal cell-death mechanisms and provides an intrinsic resistance to TKI therapy even in the presence of an activating mutation. ${ }^{35}$ Another typical example of de novo resistance is the mutation of Kirsten rat sarcoma viral oncogene homolog (KRAS). As previously stated, EGFR signaling could take two paths: the first being the PI3K/Akt pathway that supports survival, and the other being the MAPK/ERK pathway, which supports proliferation. KRAS, a key component of both of these pathways, is mutated in $\sim 30 \%$ of NSCLC. Furthermore, cancers with this mutation do not respond to either gefitinib or erlotinib. ${ }^{36}$ In fact, the utility of KRAS mutations as a biomarker for predicting resistance to TKI therapy was also investigated. ${ }^{37}$ It has been shown that mutations in EGFR and KRAS are usually mutually exclusive, ${ }^{25,38-40}$ making KRAS an independent therapeutic target. While direct attempts of drugging KRAS via farnesyl transferase inhibitors failed to show efficacy in NSCLC, ${ }^{41}$ treatment of adenocarcinomas, which are also KRAS-driven in mouse models, with the combination of a PI3K inhibitor (NVP-BEZ235) and an MAPK kinase inhibitor (ARRY-142886) showed some promise. ${ }^{42}$ Indeed, a very recent study using docetaxel in combination with either placebo or selumetinib (AZD6244, ARRY-142866) in patients with a KRAS mutation showed a 3.2 month increase in progression free survival $(\mathrm{HR}=0.58) .{ }^{43}$ This study provides some hope that targeting the MAPK pathway may also be an effective treatment for KRAS-mutant lung cancer patients in the future.

While TKIs inactivate receptor activity by binding to the intracellular kinase domain, another drug, cetuximab, a monoclonal antibody, inactivates EGFR activity by binding to the extracellular domain of EGFR. Cetuximab has been commonly used in the treatment of metastatic colorectal cancer, ${ }^{44}$ and while it is not currently FDA-approved for single-line treatment in lung cancer, early phase II trials showed a 1-month improvement of median survival time when combined with cisplatin and/or vinorelbine in NSCLC $(\mathrm{HR}=0.71) .{ }^{45}$ In a phase III trial, cetuximab was able to increase overall survival by 1.2 months $(\mathrm{HR}=0.871) .{ }^{46}$ However, a recent study combining cetuximab, carboplatin, and paclitaxel closed due to excessive high-grade toxicity events. ${ }^{47}$ Another trial compared the effects of cetuximab and radiotherapy in combination with either cisplatin and vinorelbine, or cisplatin and etoposide, and found a progression-free survival rate at $57 \%$ and $43 \%$ for each arm, respectively. ${ }^{48}$ Despite the fact that the median survival time in several studies only increased by a few months, ${ }^{49}$ the addition of cetuximab to certain combinations of conventional chemotherapy has been generally well tolerated, and continues to be investigated for use as a first-line treatment option for advanced cases of NSCLC..$^{50}$

\section{Anaplastic lymphoma kinase}

Identified as a transforming mutation in $2007,{ }^{51}$ the ALK fusion protein is a result of a chromosomal inversion, which commonly results in a fusion with echinoderm microtubule-associated protein-like 4 (EML4). Initially observed in $6.7 \%$ of Japanese patients, this mutation appears even less frequently in Koreans, African Americans, and North Americans (a mere 3\%). Early studies found that in a fraction of the cases with mutations in ALK4, ALK inhibitors may serve as a potential therapy. ${ }^{52}$ An early phase I trial of crizotinib not only showed extremely mild toxicity in treated patients but also a response rate of 57\% and 6-month progression-free survival in $72 \%$ of their patients. ${ }^{53}$ Indeed, the ALK/Met inhibitor crizotinib was conceived, tested, and finally approved by the FDA for use in NSCLC in only 4 years, and continues to show impressive results in clinical trials. ${ }^{54-56}$ This success story is extremely encouraging, 
especially compared with the early studies showing lack of efficacy with the EGFR TKIs. It is also important to highlight that in the case of gefitinib and erlotinib, the early studies that often failed to show response were evaluated in unselected populations. The phase I trial described for crizotinib showing exceedingly impressive results, and receiving partial credit for the extremely fast approval of the drug, specifically screened on their test population. Starting with 1500 patients, they narrowed down their cohort to the 82 people who actually possessed an ALK rearrangement, which resulted in a real demonstration of the drug's efficacy, and highlights the need for analysis of each and every patient.

In addition to fusing with ELM4, ALK has been shown to fuse with $\mathrm{KIF} 5 \mathrm{~B},{ }^{57} \mathrm{KLC} 1$, and is suspected to fuse with TFG, though the TFG-TRK-fused gene fusion partner still requires confirmation. ${ }^{58}$ While the effects of different fusion partners remain to be identified, all fusions result in the activation of ALK kinase activity.

\section{Resistance to ALK TKIs}

Similar to the cancers with EGFR mutations, acquired resistance (as well as an unfortunate side effect of hypogonadism and slight risk of hepatotoxicity ${ }^{59,60}$ ) is also a problem for patients with ALK4 mutations treated with crizotinib. A wide range of secondary mutations in the kinase domain, similar to the T790M mutations in EGFR, has been identified. ${ }^{61}$ These include mutations such as L1196M, S1206Y, G1202R, G1269A, D1203N, C1156Y, and L1152R. ${ }^{62-64}$ It is hypothesized that due to the fact that ALK kinase is activated by a translocation and not by a mutation within the gene, the larger range of mutations identified in the kinase domain might not affect its function. ${ }^{64}$ Alternative mechanisms of resistance include an increase in copy number and the activation of different pathways via receptor tyrosine kinase activation, such as Kit and EGFR. ${ }^{62,63}$

There are a few strategies being employed to counteract resistance. Inhibitors directed against heat-shock protein 90 (HSP90), which forms a chaperone complex with EML4ALK, are effective in interrupting the fusion protein's function. Early in vitro work and clinical trials have shown promise for HSP90 inhibition in treating lung cancers with this genotype. ${ }^{65,66}$ Very recently, a phase II trial was conducted for the HSP90 inhibitor AUY922 in several different mutation classes of NSCLC. Though the trial is ongoing, $25 \%$ of the ALK mutated patients have shown a partial response to treatment, though responders seem to be restricted to the patients with no prior treatment with crizotinib. ${ }^{67}$ However, its efficacy in cases that have already developed resistance to targeted ALK inhibitors remains to be conclusively shown. ${ }^{64,68}$ Also, there are several different kinds of ALK fusion proteins, some of which have de novo resistance to crizotinib. This, in addition to the prospect of regaining sensitivity after the development of crizotinib resistance, has sparked the development of several other ALK inhibitors targeting different sites on the kinase. Early results show that in some cases (for example the L1196M, F1174L, or G1269S mutations) an alternative ALK inhibitor may able to produce/reproduce sensitivity in NSCLC. ${ }^{64,69}$

\section{Strategies in development for lung cancer treatment}

In the search for more effective treatment for lung cancer, several genes and cellular processes were probed to identify drug targets. These include EGFR and ALK signaling, vascular endothelial growth factor (VEGF) receptors (ie, receptor tyrosine kinases involved in angiogenesis), matrix metalloproteases (which are implicated in metastasis), and insulin-like growth-factor receptors (IGFRs). ${ }^{41}$ In the following section, we describe the mechanisms and their therapeutic targets that are still under investigation (summarized in Table 1).

\section{Angiogenesis inhibitors}

The ability of a cancer to develop its own blood supply through angiogenesis is an incredibly important process, and designated as one of the "hallmarks" of cancer. ${ }^{70}$ Without angiogenesis, a tumor could not grow larger than a few millimeters, making it an attractive target for therapeutic gain. ${ }^{71}$ Several angiogenesis inhibitors, including SU5416 and thalidomide, have already failed in clinical trials, due to an unacceptable risk or pure lack of benefit. ${ }^{41,72,73}$ However, a recombinant humanized monoclonal antibody against the VEGF receptor, called bevacizumab, showed some promise, and has been included in phase II and III trials for various metastatic cancers in the last decade, ${ }^{58,74,75}$ specifically for metastatic NSCLC since $2005.76,77$ Several studies have seen increased overall survival times when combined with chemotherapy, though these studies did not account for any additional lines of therapy that may have contributed to the health of the patients. ${ }^{78}$ While high toxicity occurred in squamous carcinomas, adenocarcinomas tended to respond with minimal adverse side affects. ${ }^{78}$ A recent phase II single-arm trial found that a combination of bevacizumab and platinum-based chemotherapy followed by maintenance therapy was able to extend progression-free survival to 7.1 months, and median survival time to 17.1 months in $85 \%$ of the patients. ${ }^{79}$ While this is still an improvement 
Table I Summary of the current therapies, their targets, and their function

\begin{tabular}{llll}
\hline Drug & Class & Target & Pathway \\
\hline Gefitinib, erlotinib & Tyrosine kinase inhibitor & EGFR & PI3K/Akt - survival \\
Cetuximab & Monoclonal antibody & MAPK - proliferation \\
& & EGFR & PI3K - survival \\
Crizotinib & Tyrosine kinase inhibitor & ALK & MAPK - proliferation \\
Bevacizumab & Monoclonal antibody & VEGF & MAPK - proliferation \\
Sunitinib, sorafenib & Tyrosine kinase inhibitor & VEGF & Angiogenesis \\
Vorinostat & Small molecule inhibitor & Histone deacetylase & Angiogenesis \\
Cixutumumab & Tyrosine kinase inhibitor & IGF-IR & Epigenetic silencing \\
Figitumumab & Monoclonal antibody & IGF-IR & PI3K/Akt, DNA damage \\
Celecoxib & Small molecule inhibitor & COX-2 & PI3K/Akt, DNA damage \\
\hline
\end{tabular}

Abbreviations: EGFR, epidermal growth factor receptor; VEGF, vascular endothelial growth factor; IGF, insulin-like growth factor; PI3K, phosphatidylinositide 3-kinase; MAPK, mitogen-activated protein kinase; COX-2, Cyclooxygenase-2.

over the existing therapies, a major disadvantage is that this therapy does not seem to render any benefit to patients over the age of 65 years, which is the main demographic group for lung cancer. ${ }^{1,80,81}$ However, recent studies have shown that in a small cohort of non-squamous NSCLC selected patients (at an average age of 65 years), bevacizumab in addition to docetaxel as a second-line or above therapy was able to produce a median progression-free survival time of 7.9 months and control disease in $95 \%$ of the patients. ${ }^{82}$ This warrants further investigation as to the usefulness of bevacizumab in this age-group. Along a parallel path, several other TKIs directed against angiogenesis, such as sunitinib, sorafenib, and linifanib, are also in clinical trials. While they are intended to inhibit VEGF, they are nonspecific, and therefore could also inhibit other kinases, such as platelet-derived growth factor receptor and Kit. ${ }^{83}$ Early phase II trials showed some positive activity against recurrent NSCLC, though the benefit gained by these agents was only in the order of months..$^{84,85} \mathrm{~A}$ recent phase II trial tested the addition of linifanib or placebo to a combination of carboplatin and paclitaxel therapy for nonsquamous NSCLC. At lower doses of linifanib, progressionfree survival was improved by 2.9 months $(\mathrm{HR}=0.51)$; however, overall survival was not greatly improved ${ }^{86}$ This is contradictory to a phase III trial of sorafenib, which seemed to show no benefit ${ }^{87}$ However, a recurrent explanation provided in the literature for the failure of the trials is due to the lack of patient selection by biomarkers that would respond well to anti-VEGF agents. ${ }^{88,89}$

\section{Histone deacetylase inhibitor}

Recently there has been some investigation into drugs that can inhibit histone deacetylases (HDACs) as therapeutics. HDACs are responsible for removing acetyl groups from histones. This helps to condense chromatin, and in the case of cancer often shuts down crucial genes involved in proliferative regulation..$^{90,91}$ In a phase I trial, treating a small cohort $(\mathrm{n}=19)$ with an HDAC inhibitor, vorinostat, produced response in $53 \%$ of patients, compared to the $20 \%-30 \%$ response rate of chemotherapy. Following up with in vitro testing of the effects of vorinostat with carboplatin and paclitaxel showed a synergistic benefit. ${ }^{91}$ Another in vitro study found that the effects of vorinostat on cancer cells could be due in part to its effects on telomerases, a protein required to maintain the immortality of cells. ${ }^{92}$ While it is still too early to tell how quickly resistance might be acquired, and the mechanisms thereof, the results of future phase II and III trials are eagerly awaited.

\section{Insulin-like growth-factor I receptor inhibitor (IGF-IR)}

IGF-1R is yet another TKI that can initiate proliferative as well as antiapoptotic signaling in the cell. The finding that IGF-1R is overexpressed in a wide range of cancers made it an interesting target. ${ }^{93} \mathrm{~A}$ drug designed to inhibit IGF-IR, IMC-A12 (later called cixutumumab [CIX]), is a human monoclonal antibody, which was identified to have tumorsuppressive potential. ${ }^{94}$ It is thought that IGF-1R is centrally placed in several different survival signaling mechanisms, which leads to increased resistance to cytotoxic agents. These include the Akt/PI3K pathway, and activation of p38 and Rad51, which increase DNA-damage repair. ${ }^{94}$ CIX began early clinical trials by being combined with chemotherapy as a method to regain sensitivity to chemotherapy. ${ }^{95}$ Of these trials, those specifically aimed at NSCLC were phase I or II trials using CIX in various combinations with erlotinib, cetuximab, and chemotherapy. However, no reports were found to have noteworthy success. A recent phase I/II trial 
also suggested that the combination of CIX with erlotinib in nonselected patients had high toxicity and little benefit. ${ }^{96}$

Despite the seeming failure of CIX, a slew of other IGF-1R inhibitors have been developed. ${ }^{97}$ Another IGF-1R monoclonal antibody - CP-751871, better known as figitumumab - was able to increase objective response by $12 \%$ and progression-free survival by 1 month $(\mathrm{HR}=0.46)$ when combined with carboplatin and paclitaxel in a recent phase II study. Of note, it seemed that those with squamous cell lung cancer were particularly responsive. ${ }^{98}$ Despite early optimism, phase III trials were discontinued due to lack of benefit. However, the search for biomarkers to identify the appropriate patient population began. Currently, it is thought that circulating levels of IGF-1 might be useful in identifying possible beneficiaries of figitumumab treatment. ${ }^{99}$

\section{Cyclooxygenase-2 inhibitor}

Cyclooxygenase 2 (COX-2) is a member of the COX family of enzymes that are involved in the production of prostaglan$\operatorname{din} \mathrm{H}_{2}\left(\mathrm{PGH}_{2}\right)$. In NSCLC, the expression of COX-2 has been highly correlated with increased survivin, an antiapoptotic factor, ${ }^{100}$ and COX-2 has been found to be overexpressed in $\sim 90 \%$ of NSCLC patient samples. ${ }^{101}$ Once COX-2 produces $\mathrm{PGH}_{2}, \mathrm{PGH}_{2}$ can then be converted to $\mathrm{PGE}_{2}$. Increased $\mathrm{PGE}_{2}$ levels lead to increased EGFR signaling, which in turn promotes survival and proliferation. Elevated $\mathrm{PGE}_{2}$ levels have been correlated with neoplastic lung tissues, ${ }^{102}$ making COX-2 and its signaling pathway an attractive target for therapy. Early phase II studies found that in unselected patients, the use of celecoxib, a COX-2 inhibitor, did not render any benefit; however, a possible biomarker for response was identified. ${ }^{103}$ Unfortunately, there does not seem to be a large body of evidence that celecoxib could be useful in the treatment of NSCLC, but studies have been conducted looking at its use as a cancer preventative, rather than a cure. One study found that celecoxib given to former smokers not only showed a decrease in biomarkers of early carcinogenesis but also showed a reduction in lung nodules. ${ }^{104}$

While the inhibition of $\mathrm{PGH}_{2}$ is desired in order to decrease $\mathrm{PHE}_{2}$ levels, $\mathrm{PGH}_{2}$ can alternatively be made into prostacyclin $\left(\mathrm{PGI}_{2}\right)$, if $\mathrm{PGI}_{2}$ synthase is present. Unlike $\mathrm{PGE}_{2}, \mathrm{PGI}_{2}$ has actually been shown to have a tumorsuppressive function. $\mathrm{PGI}_{2}$ synthase, however, is downregulated in many NSCLCs, resulting in low levels of PGI ${ }_{2}{ }^{105}$ Recent studies have investigated the possible use of $\mathrm{PGI}_{2}$ as a chemoprevention strategy, finding that in mouse models increasing $\mathrm{PGI}_{2}$ (alone and with gefitinib in moderate doses) prevented tumorigenesis. ${ }^{106,107}$ Additionally, studies in mouse models found that the activation of peroxisome proliferator-activated receptor gamma (PPAR $\gamma$ ) was in part responsible for the tumor-suppressive phenotype of $\mathrm{PGI}_{2} \cdot{ }^{108}$ PPAR $\gamma$ is a potent transcription factor, which has roles in suppressing inflammatory and immune responses, ${ }^{109}$ as well as directing the differentiation of adipocytes. Low PPAR $\gamma$ in NSCLC has also been correlated with poor prognosis. ${ }^{110}$ Additionally, a large trial looking at patients across ten Veterans Affairs medical centers compared patients using thiazolidinediones (which are ligands for PPAR $\gamma$ activation) to those who were not on the drug. The investigators found that those individuals taking thiazolidinediones had a $33 \%$ reduced risk for lung cancer, highlighting PPAR $\gamma$ as a possible target warranting further investigation for clinical application. ${ }^{111}$

As previously mentioned, the prevalence of the EGFR and ALK mutations that are currently targetable by therapy can account for only a small percentage of NSCLC patients, and current treatments are only useful for a short period of time due to resistance. The concept of reversing resistance (sensitization) has driven an appreciable amount of research in this area. For example, there have been studies showing that a combination of erlotinib with cetuximab can induce apoptosis in formerly TKI-resistant cells in vitro. ${ }^{112}$

In general, the idea of combinatorial therapeutics is becoming more popular. Though EGFR treatments, as previously discussed, are looking at combinatorial-targeted inhibition, $S r c$, the first discovered oncogene, and its downstream effects also closely mirror that of many of the receptor tyrosine kinases. To that end, a recent study attempting to concomitantly target Src and EGFR has shown some promising initial results. In a small trial, the inhibition of Src with different doses of dasatinib (all combined with erlotinib) in patients with lung cancer (50\% adenocarcinoma, $21 \%$ squamous cell histology, $29 \%$ NSCLC) was seen to have a favorable response in 29 of 34 patients treated, as evinced by a disease-control rate (partial response plus stable disease) of $62 \%$ of patients, with a median progression-free survival time of 2.7 months and an overall survival time of 5.6 months (ranging from 4.9 to 12.2 months). This trial also determined that dasatinib may be combined safely with erlotinib for treatment. ${ }^{113}$

However, even combinatorial treatments might not be effective for all cases. Given the propensity of cancer to develop resistant cells, the next logical step in preventing relapse would be to target multiple pathways, or rather attacking cancer as a heterogeneous body. Perhaps targeting the primary and common resistance mechanisms simultaneously 
could improve the treatments. A recent study did just this, adding a c-Met inhibitor, tivantinib, to erlotinib. Though it was a small phase I trial, and further studies are being conducted, all 13 of their patients were able to achieve either a partial response or stable disease. ${ }^{114}$ Several examples in the literature describe cases where two distinct driving mechanisms have been found in clonal populations within the same cancer, also suggesting that combination therapy might be the best approach to treatment. ${ }^{52,64}$ Combination of erlotinib and the VEGF inhibitor sorafenib has shown early promise in phase II trials. ${ }^{15}$ Conversely, combination of erlotinib with another VEGF inhibitor, sunitinib, did not have any effect in a phase III trial. ${ }^{116}$ In several of these cases, the clonal populations of cells with different driving mutations, and those with new mutations, gained resistance, and tended to fall into categories for which targeted therapies already exist in NSCLC (Figure 1). For example, a patient who develops lung cancer with an ALK fusion protein and treated with crizotinib may have their lung tumors shrink, but subsequently develop a resistant population of cells, via EGFR mutations. In that case, since crizotinib would no longer be effective for this patient, treatment with gefitinib or erlotinib might be beneficial. Another example would be a case where the lung cancer driven by an EGFR mutation develops resistance to therapy by the upregulation of Met. In that case, the cancer may now be sensitive to a subsequent treatment with crizotinib. ${ }^{28,29,64}$ Given the advances in personalized medicine

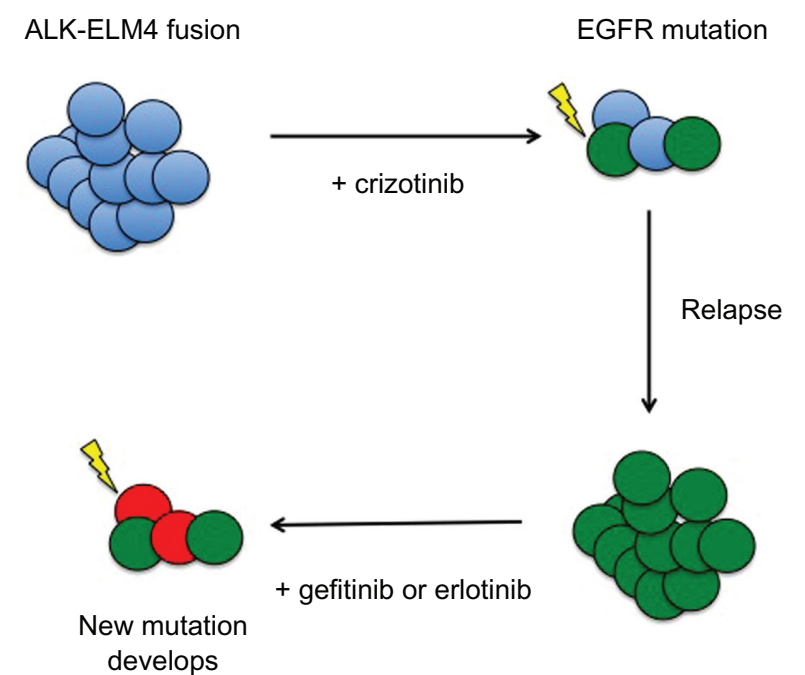

Figure I A hypothetical line of treatment based on the availability of a range of targeted therapies.

Notes: An initial tumor is treated with its appropriate therapy. Upon resistance via mutations or clonal selection, the cancer can be sensitized with a different drug. This process of personalized medicine might not cure the disease, but rather keeps the disease under constant submission.

Abbreviations: ALK, anaplastic lymphoma kinase; ELM4, echinoderm microtubuleassociated protein-like 4; EGFR, epidermal growth factor receptor. via genetic and biomarker screening, we may be much more effective at treating these various scenarios.

\section{Future directions for the treatment of lung cancer}

While the kinase pathways have been the major focus of therapeutic development, recently a small body of literature is suggestive of an important role for the Wnt-signaling pathway in lung cancer. The common conversation about Wnt signaling references the canonical pathway, where binding of a Wnt ligand to a Frizzled receptor results in stabilization of $\beta$-catenin. Normally important as a structural protein, when $\beta$-catenin is allowed to persist in the cytosol, it translocates into the nucleus, where it stimulates not only the genes associated with increased proliferation and motility but also factors that are native to stem cells. While this transcriptional program is very important during development, improper activation in adult tissues contributes to oncogenesis. ${ }^{117-119}$ Therefore, attempts to use this pathway as a target for therapeutic gain have all been focused on inhibiting canonical signaling. ${ }^{120,121}$ Interestingly, recent studies have identified a possible benefit in NSCLC, not from inhibiting Wnt signaling, but from restoring its function.

Specifically, Wnt 7a, when paired with the receptor Frizzled 9 , activates a $\beta$-catenin independent (noncanonical) signaling pathway. This leads to a cascade of events including the activation of c-Jun N-terminal kinase signaling, ${ }^{122}$ Sprouty-4 (a TKI), ${ }^{122,123}$ and the stabilization of PPAR $\gamma .{ }^{117,123}$ Intriguingly, Wnt 7a is lost in a high percentage of NSCLC. In fact, a staggering $85 \%$ of patient tissue samples and $88 \%$ of dysplastic lesions have lost Wnt $7 \mathrm{a}$, possibly via DNA methylation-mediated gene silencing. ${ }^{124}$ Moreover, it was also observed that the reconstitution of this noncanonical Wnt-signaling pathway displayed significant tumorsuppressive effects. ${ }^{122}$ These factors make this pathway an exciting prospect not only for its possible efficacy in treatment but also for its widespread applicability.

However, it is a challenge to purify recombinant Wnt 7a that can be used in therapy. Interestingly, it has been shown that a $\mathrm{PGI}_{2}$ analogue ${ }^{125}$ can mimic many of the effects of Wnt 7a in the context of Frizzled 9. Recent studies have also shown that the addition of prostacyclin to lung cancer cell lines that have retained Wnt 7 a receptor Frizzled 9 results in decreased proliferation, inhibition of anchorage-independent growth, ${ }^{126}$ and significantly decreases lung cancer growth in vitro. ${ }^{123,126}$

While the Wnt pathway presents an exciting new path to investigate, we must also continue to find new and different 
targets in the treatment of lung cancer. New methods are currently in development to assist in the screening of individual patients for important mutations, which may help identify which therapy would be effective for them. ${ }^{127,128}$ Additionally, steps have been taken towards identifying novel mutations that still require therapeutic development via whole-genome analysis methods. Recent studies in SCLC have analyzed the genomes, transcriptomes, and exomes of SCLC samples, either alone or paired to normal tissues. By looking at the entire cancer rather than just the mutations that have been previously reported, several trends emerged and pointed towards new targets. ${ }^{129,130}$ This method has also been applied to NCSLCs, specifically of the squamous histology type. Of the 178 lung squamous cell carcinomas that were characterized, eleven genes among hundreds of alterations in gene copy number, gene rearrangements, and mutations were recurrently mutated. While these include some of the obvious suspects, such as TP53, alternate pathways were also found to be commonly mutated, including proteins important for cellular differentiation and oxidative stress. ${ }^{131}$ If the goal of achieving truly personalized medicine requires that we screen each and every patient in order to ascertain their therapeutic needs, we then also need to prepare therapies for any number of possible mutant genotypes so that once the problem is identified, we can be equipped to treat it.

\section{Discussion}

Lung cancer remains the leading cause of cancer deaths in the United States. While there have been a number of drugs approved for use, they have suffered from limited applicability and an incredibly high rate of acquired resistance. At the current rate, real advancement in the treatment of lung cancer may still be years or even decades away. That being said, several themes have emerged in the literature. First, there is a significant need for the advancement of personalized medicine. The power of targeted therapies is clear when applied to those individuals harboring the specific mutations for which the drug was designed to treat. However, the success of many of these targeted therapies has often been confounded by the design of the trials. The low prevalence of mutations that are specifically targeted by drugs result in trials that mask efficacy in large and unselected populations of patients. This highlights the need for a more personalized approach to therapy. The identification of biomarkers is progressing, but will do little good if the information is not translated to the clinical trial arena, allowing drugs to be tested against their intended population. The perfect example of this was previously described in the cases of gefitinib and crizotinib. The selection of patients via the use of biomarkers and individualized analysis can mean the difference between a null result and the clear demonstration of a medicine's potential.

Secondly, there is no magic bullet for any of these subsets of cancers. Where one mutation may dominate, other populations will rise or adapt upon selection by drugs. While there may not be a single cure for lung cancer, there could be a way to either cycle treatment or combine drugs in such a way as to keep the cancer cells under constant submission. This also requires that attention be paid to the patient on an individual basis, as the mechanisms of resistance are many, and proper treatment relies on the ability to determine which resistance mechanism has been employed. Based on the adaptive nature of lung cancer, one must constantly be vigilant in looking for alternative mechanisms to target this disease, and the need to develop more robust personalized approaches for the treatment of lung cancer has never been greater.

\section{Acknowledgments}

This study was supported by a merit award from the US Department of Veterans Affairs, and National Institute of Health grants R01CA1385282522717 and 5R21CA15326802 to Robert A Winn.

\section{Disclosure}

The authors have no conflicts of interest to disclose.

\section{References}

1. Siegel R, Naishadham D, Jemal A. Cancer statistics, 2012. CA Cancer J Clin. 2012;62:10-29.

2. Okubo K, Mark EJ, Flieder D, et al. Bronchoalveolar carcinoma: clinical, radiologic, and pathologic factors and survival. $J$ Thorac Cardiovasc Surg. 1999;118:702-709.

3. Raz DJ, He B, Rosell R, Jablons DM. Current concepts in bronchioloalveolar carcinoma biology. Clin Cancer Res. 2006;12:3698-3704.

4. Siegel R, DeSantis C, Virgo K, et al. Cancer treatment and survivorship statistics, 2012. CA Cancer J Clin. 2012;62:220-241.

5. Khuri FR, Herbst RS, Fossella FV. Emerging therapies in non-smallcell lung cancer. Ann Oncol. 2001;12:739-744.

6. Weinstein IB. Cancer. Addiction to oncogenes - the Achilles heal of cancer. Science. 2002;297:63-64.

7. Habeck M. FDA licences imatinib mesylate for CML. Lancet Oncol. 2002;3:6.

8. Carpenter G, Cohen S. Epidermal growth factor. J Biol Chem. 1990;265: 7709-7712.

9. Cohen MH, Williams GA, Sridhara R, Chen G, Pazdur R. FDA drug approval summary: gefitinib (ZD1839) (Iressa) tablets. Oncologist. 2003;8:303-306.

10. Cohen MH, Johnson JR, Chen YF, Sridhara R, Pazdur R. FDA drug approval summary: erlotinib (Tarceva) tablets. Oncologist. 2005;10: 461-466.

11. Thatcher N, Chang A, Parikh P, et al. Gefitinib plus best supportive care in previously treated patients with refractory advanced non-small-cell lung cancer: results from a randomised, placebo-controlled, multicentre study (Iressa Survival Evaluation in Lung Cancer). Lancet. 2005;366: 1527-1537. 
12. Shepherd FA, Rodrigues Pereira J, Ciuleanu T, et al. Erlotinib in previously treated non-small-cell lung cancer. $N$ Engl J Med. 2005;353: 123-132.

13. Gazdar AF. Activating and resistance mutations of EGFR in non-smallcell lung cancer: role in clinical response to EGFR tyrosine kinase inhibitors. Oncogene. 2009;28 Suppl 1:S24-S31.

14. Lynch TJ, Bell DW, Sordella R, et al. Activating mutations in the epidermal growth factor receptor underlying responsiveness of non-small-cell lung cancer to gefitinib. N Engl J Med. 2004;350:2129-2139.

15. Marchetti A, Martella C, Felicioni L, et al. EGFR mutations in nonsmall-cell lung cancer: analysis of a large series of cases and development of a rapid and sensitive method for diagnostic screening with potential implications on pharmacologic treatment. $J$ Clin Oncol. 2005;23:857-865.

16. Paez JG, Jänne PA, Lee JC, et al. EGFR mutations in lung cancer: correlation with clinical response to gefitinib therapy. Science. 2004;304:1497-1500.

17. Wu YL, Zhong WZ, Li LY, et al. Epidermal growth factor receptor mutations and their correlation with gefitinib therapy in patients with non-small cell lung cancer: a meta-analysis based on updated individual patient data from six medical centers in mainland China. $J$ Thorac Oncol. 2007;2:430-439.

18. Shao YY, Lin CC, Yang CH. Gefitinib or erlotinib in the treatment of advanced non-small cell lung cancer. Discov Med. 2010;9: 538-545.

19. Costa EC, Taron M, Queralt C, et al. Differential progression-free survival (PFS) to erlotinib according to EGFR exon 19 deletion type in non-small cell lung cancer (NSCLC) patients (p) in the EURTAC study. J Clin Oncol. 2012;30 Suppl:7540.

20. Mok TS, Wu YL, Thongprasert S, et al. Gefitinib or carboplatin-paclitaxel in pulmonary adenocarcinoma. $N$ Engl J Med. 2009;361:947-957.

21. Oxnard GR, Arcila ME, Sima CS, et al. Acquired resistance to EGFR tyrosine kinase inhibitors in EGFR-mutant lung cancer: distinct natural history of patients with tumors harboring the T790M mutation. Clin Cancer Res. 2011;17:1616-1622.

22. Rosell R, Moran T, Queralt C, et al. Screening for epidermal growth factor receptor mutations in lung cancer. $N$ Engl J Med. 2009;361: 958-967.

23. Yun $\mathrm{CH}$, Mengwasser $\mathrm{KE}$, Toms $\mathrm{AV}$, et al. The T790M mutation in EGFR kinase causes drug resistance by increasing the affinity for ATP. Proc Natl Acad Sci U S A. 2008;105:2070-2075.

24. Pao W, Miller VA, Politi KA, et al. Acquired resistance of lung adenocarcinomas to gefitinib or erlotinib is associated with a second mutation in the EGFR kinase domain. PLoS Med. 2005;2:e73.

25. Kosaka T, Yatabe Y, Endoh H, et al. Analysis of epidermal growth factor receptor gene mutation in patients with non-small cell lung cancer and acquired resistance to gefitinib. Clin Cancer Res. 2006;12: 5764-5769.

26. Hammerman PS, Janne PA, Johnson BE. Resistance to epidermal growth factor receptor tyrosine kinase inhibitors in non-small cell lung cancer. Clin Cancer Res. 2009;15:7502-7509.

27. Suda K, Mizuuchi H, Maehara Y, Mitsudomi T. Acquired resistance mechanisms to tyrosine kinase inhibitors in lung cancer with activating epidermal growth factor receptor mutation-diversity, ductility, and destiny. Cancer Metastasis Rev. 2012;31:807-814.

28. Engelman JA, Zejnullahu K, Mitsudomi T, et al. MET amplification leads to gefitinib resistance in lung cancer by activating ERBB3 signaling. Science. 2007;316:1039-1043.

29. Cappuzzo F, Jänne PA, Skokan M, et al. MET increased gene copy number and primary resistance to gefitinib therapy in non-small-cell lung cancer patients. Ann Oncol. 2009;20:298-304.

30. Kosaka T, Yamaki E, Mogi A, Kuwano H. Mechanisms of resistance to EGFR TKIs and development of a new generation of drugs in nonsmall-cell lung cancer. J Biomed Biotechnol. 2011;2011:165214.

31. Sos ML, Koker M, Weir BA, et al. PTEN loss contributes to erlotinib resistance in EGFR-mutant lung cancer by activation of Akt and EGFR. Cancer Res. 2009;69:3256-3261.
32. Thomson S, Buck E, Petti F, et al. Epithelial to mesenchymal transition is a determinant of sensitivity of non-small-cell lung carcinoma cell lines and xenografts to epidermal growth factor receptor inhibition. Cancer Res. 2005;65:9455-9462.

33. Chang TH, Tsai MF, Su KY, et al. Slug confers resistance to the epidermal growth factor receptor tyrosine kinase inhibitor. Am J Respir Crit Care Med. 2011;183:1071-1079.

34. Winn RA, Tuder RM. "Un-slugging" resistance to epidermal growth factor receptor inhibition. A positive outlook for the future of lung cancer therapy. Am J Respir Crit Care Med. 2011;183:970-972.

35. Ng KP, Hillmer AM, Chuah CT, et al. A common BIM deletion polymorphism mediates intrinsic resistance and inferior responses to tyrosine kinase inhibitors in cancer. Nat Med. 2012;18:521-528.

36. Pao W, Wang TY, Riely GJ, et al. KRAS mutations and primary resistance of lung adenocarcinomas to gefitinib or erlotinib. PLoS Med. 2005;2:e17.

37. Massarelli E, Varella-Garcia M, Tang X, et al. KRAS mutation is an important predictor of resistance to therapy with epidermal growth factor receptor tyrosine kinase inhibitors in non-small-cell lung cancer. Clin Cancer Res. 2007;13:2890-2896.

38. Schmid K, Oehl N, Wrba F, Pirker R, Pirker C, Filipits M. EGFR/ KRAS/BRAF mutations in primary lung adenocarcinomas and corresponding locoregional lymph node metastases. Clin Cancer Res. 2009; 15:4554-4560.

39. Shigematsu H, Lin L, Takahashi T, et al. Clinical and biological features associated with epidermal growth factor receptor gene mutations in lung cancers. J Natl Cancer Inst. 2005;97:339-346.

40. Kris MG, Johnson BE, Kwiatkowski, et al. Identification of driver mutations in tumor specimens from 1,000 patients with lung adenocarcinoma: the NCI's Lung Cancer Mutation Consortium (LCMC). J Clin Oncol. 2011;29 Suppl:CRA7506.

41. Broker LE, Giaccone G. The role of new agents in the treatment of non-small cell lung cancer. Eur J Cancer. 2002;38:2347-2361.

42. Engelman JA, Chen L, Tan X, et al. Effective use of PI3K and MEK inhibitors to treat mutant Kras G12D and PIK3CA H1047R murine lung cancers. Nat Med. 2008;14:1351-1356.

43. Jänne PA, Shaw AT, Pereira JR, et al. Efficacy and patient (pt)-reported outcomes (PROs) with selumetinib (AZD6244, ARRY-142866; SEL) + docetaxel (Doc) in KRAS-mutant advanced non-small cell lung cancer (NSCLC): a randomized, phase II trial. Ann Oncol. 2012;23 Suppl 9: 1233PD.

44. Ramalingam S, Belani CP. Recent advances in targeted therapy for nonsmall cell lung cancer. Expert Opin Ther Targets. 2007;11:245-257.

45. Rosell R, Robinet G, Szczesna A, et al. Randomized phase II study of cetuximab plus cisplatin/vinorelbine compared with cisplatin/ vinorelbine alone as first-line therapy in EGFR-expressing advanced non-small-cell lung cancer. Ann Oncol. 2008;19:362-369.

46. Pirker R, Pereira JR, Szczesna A, et al. Cetuximab plus chemotherapy in patients with advanced non-small-cell lung cancer (FLEX): an openlabel randomised phase III trial. Lancet. 2009;373:1525-1531.

47. Hanna NH, Dahlberg SE, Kolesar J, et al. Three-arm randomized phase II study of carboplatin (C) and paclitaxel (P) in combination with cetuximab (CET), IMC-A12, or both for advanced non-small cell lung cancer (NSCLC) patients who will not receive bevacizumabbased therapy: an Eastern Cooperative Oncology Group (ECOG) study (E4508). J Clin Oncol. 2012;30 Suppl:7516.

48. Greillier L, Martel-Lafay I, Arpin D, et al. A randomised phase II study of cetuximab (c) in combination with two cisplatin-based concurrent chemoradiotherapy regimens in patients (pts) with stage III non-small cell lung cancer (NSCLC). Final results of the GFPC 08-03 trial. Paper presented at the 37th European Society for Medical Oncology (ESMO) Congress; September 28-October 2, 2012; Vienna, Austria.

49. Gridelli C, Maione P, Ferrara ML, Rossi A. Cetuximab and other antiepidermal growth factor receptor monoclonal antibodies in the treatment of non-small cell lung cancer. Oncologist. 2009;14:601-611.

50. Ma PC. Personalized targeted therapy in advanced non-small cell lung cancer. Cleve Clin J Med. 2012;79 Suppl 1:eS56-eS60. 
51. Soda M, Choi YL, Enomoto M, et al. Identification of the transforming EML4-ALK fusion gene in non-small-cell lung cancer. Nature. 2007;448:561-566.

52. Koivunen JP, Mermel C, Zejnullahu K, et al. EML4-ALK fusion gene and efficacy of an ALK kinase inhibitor in lung cancer. Clin Cancer Res. 2008; 14:4275-4283.

53. Kwak EL, Bang YJ, Camidge DR, et al. Anaplastic lymphoma kinase inhibition in non-small-cell lung cancer. $N$ Engl J Med. 2010;363: 1693-1703.

54. Forde PM, Rudin CM. Crizotinib in the treatment of non-small-cell lung cancer. Expert Opin Pharmacother. 2012;13:1195-1201.

55. Galetta D, Rossi A, Pisconti S, Colucci G. The emerging role of ALK inhibitors in the treatment of advanced non-small cell lung cancer. Expert Opin Ther Targets. 2012;16 Suppl 2:S45-S54.

56. Kimura $\mathrm{H}$, et al. ALK fusion gene positive lung cancer and 3 cases treated with an inhibitor for ALK kinase activity. Lung Cancer. 2012;75: 66-72.

57. Takeuchi K, Choi YL, Togashi Y, et al. KIF5B-ALK, a novel fusion oncokinase identified by an immunohistochemistry-based diagnostic system for ALK-positive lung cancer. Clin Cancer Res. 2009; 15:3143-3149.

58. Togashi Y, Soda M, Sakata S, et al. KLC1-ALK: a novel fusion in lung cancer identified using a formalin-fixed paraffin-embedded tissue only. PLoS One. 2012;7:e31323.

59. Weickhardt AJ, Rothman MS, Salian-Mehta S, et al. Rapid-onset hypogonadism secondary to crizotinib use in men with metastatic nonsmall cell lung cancer. Cancer. 2012;118:5302-5309.

60. Schnell P, Safferman AZ, Bartlett CH, Tang Y, Wilner KD. Clinical presentation of hepatotoxicity-associated crizotinib in ALK-positive (ALK+) advanced non-small cell lung cancer (NSCLC). J Clin Oncol. 2012;30 Suppl:7598.

61. Zhang S, Wang F, Keats J, et al. Crizotinib-resistant mutants of EML4ALK identified through an accelerated mutagenesis screen. Chem Biol Drug Des. 2011;78:999-1005.

62. Doebele RC, Pilling AB, Aisner DL, et al. Mechanisms of resistance to crizotinib in patients with ALK gene rearranged non-small cell lung cancer. Clin Cancer Res. 2012;18:1472-1482.

63. Katayama R, Shaw AT, Khan TM, et al. Mechanisms of acquired crizotinib resistance in ALK-rearranged lung cancers. Sci Transl Med. 2012;4:120ra17.

64. Camidge DR, Doebele RC. Treating ALK-positive lung cancer early successes and future challenges. Nat Rev Clin Oncol. 2012;9: 268-277.

65. Chen Z, Sasaki T, Tan X, et al. Inhibition of ALK, PI3K/MEK, and HSP90 in murine lung adenocarcinoma induced by EML4-ALK fusion oncogene. Cancer Res. 2010;70:9827-9836.

66. Katayama R, Khan TM, Benes C, et al. Therapeutic strategies to overcome crizotinib resistance in non-small cell lung cancers harboring the fusion oncogene EML4-ALK. Proc Natl Acad Sci U S A. 2011;108: 7535-7540

67. Garon EB, Moran T, Barlesi F, et al. Phase II study of the HSP90 inhibitor AUY922 in patients with previously treated, advanced non-small cell lung cancer (NSCLC). J Clin Oncol. 2012; 30 Suppl:7543.

68. Sasaki T, Janne PA. New strategies for treatment of ALK-rearranged non-small cell lung cancers. Clin Cancer Res. 2011;17:7213-7218.

69. Heuckmann JM, Hölzel M, Sos ML, et al. ALK mutations conferring differential resistance to structurally diverse ALK inhibitors. Clin Cancer Res. 2011;17:7394-7401.

70. Hanahan D, Weinberg RA. The hallmarks of cancer. Cell. 2000;100: 57-70.

71. Folkman J. What is the evidence that tumors are angiogenesis dependent? J Natl Cancer Inst. 1990;82:4-6.

72. Reck M, Gatzemeier U. Targeted therapies: thalidomide in lung cancer therapy - what have we learned? Nat Rev Clin Oncol. 2010;7: $134-135$.
73. Hoang T, Dahlberg SE, Schiller JH, et al. Randomized phase III study of thoracic radiation in combination with paclitaxel and carboplatin with or without thalidomide in patients with stage III non-small-cell lung cancer: the ECOG 3598 study. J Clin Oncol. 2012;30:616-622.

74. Yang JC, Haworth L, Sherry RM, et al. A randomized trial of bevacizumab, an anti-vascular endothelial growth factor antibody, for metastatic renal cancer. N Engl J Med. 2003;349:427-434.

75. Kindler HL, Shulman KL. Metastatic colorectal cancer. Curr Treat Options Oncol. 2001;2:459-471.

76. Azim HA Jr, Ganti AK. Targeted therapy in advanced non-small cell lung cancer (NSCLC): where do we stand? Cancer Treat Rev. 2006;32:630-636.

77. Laskin JJ, Sandler AB. First-line treatment for advanced non-small-cell lung cancer. Oncology (Williston Park). 2005;19:1671-1676; discussion $1678-1680$.

78. Dempke WC, Suto T, Reck M. Targeted therapies for non-small cell lung cancer. Lung Cancer. 2010;67:257-274.

79. Stevenson JP, Langer CJ, Somer RA, et al. Phase 2 trial of maintenance bevacizumab alone after bevacizumab plus pemetrexed and carboplatin in advanced, nonsquamous nonsmall cell lung cancer. Cancer. 2012;118:5580-5587.

80. Roehr B. Bevacizumab as adjuvant therapy for lung cancer does not help patients over 65. BMJ. 2012;344:e2855.

81. Dasanu CA. Bevacizumab in lung cancer: lackluster performance and unjustified expense? J Oncol Pharm Pract. 2012;18:381-382.

82. Ohyanagi F, Tanimoto A, Sakatani T, et al. Phase II trial of bevacizumab plus docetaxel in patients with previously treated nonsquamous nonsmall cell lung cancer. J Clin Oncol. 2012;30 Suppl:e18004.

83. Ramalingam SS, Owonikoko TK, Khuri FR. Lung cancer: new biological insights and recent therapeutic advances. CA Cancer J Clin. 2011;61: 91-112.

84. Gridelli C, Maione P, Del Gaizo F, et al. Sorafenib and sunitinib in the treatment of advanced non-small cell lung cancer. Oncologist. 2007; 12:191-200.

85. Tan EH, Goss GD, Salgia R, et al. Phase 2 trial of Linifanib (ABT-869) in patients with advanced non-small cell lung cancer. J Thorac Oncol. 2011;6:1418-1425.

86. Ramalingam SS, Shtivelband M, Soo RA, et al. Randomized phase II study of carboplatin and paclitaxel with either linifanib or placebo for advanced nonsquamous NSCLC. J Clin Oncol. 2012;30 Suppl:7512.

87. Paz-Ares LG, Biesma B, Heigener D, et al. Phase III, randomized, double-blind, placebo-controlled trial of gemcitabine/cisplatin alone or with sorafenib for the first-line treatment of advanced, nonsquamous non-small-cell lung cancer. J Clin Oncol. 2012;30:3084-3092.

88. Bria E, Pilotto S, Tortora G. Sorafenib for lung cancer: is the "Battle" still open? Expert Opin Investig Drugs. 2012;21:1445-1448.

89. Zhang J, Gold KA, Kim E. Sorafenib in non-small cell lung cancer. Expert Opin Investig Drugs. 2012;21:1417-1426.

90. Neal JW, Sequist LV. Exciting new targets in lung cancer therapy: ALK, IGF-1R, HDAC, and Hh. Curr Treat Options Oncol. 2010;11: 36-44.

91. Owonikoko TK, Ramalingam SS, Kanterewicz B, Balius TE, Belani CP, Hershberger PA. Vorinostat increases carboplatin and paclitaxel activity in non-small-cell lung cancer cells. Int J Cancer. 2010;126:743-755

92. Li CT, Hsiao YM, Wu TC, Lin YW, Yeh KT, Ko JL. Vorinostat, SAHA, represses telomerase activity via epigenetic regulation of telomerase reverse transcriptase in non-small cell lung cancer cells. J Cell Biochem. 2011;112:3044-3053.

93. Ouban A, Muraca P, Yeatman T, Coppola D. Expression and distribution of insulin-like growth factor-1 receptor in human carcinomas. Hum Pathol. 2003;34:803-808.

94. Rowinsky EK, Youssoufian H, Tonra JR, Solomon P, Burtrum D, Ludwig DL. IMC-A12, a human IgG1 monoclonal antibody to the insulin-like growth factor I receptor. Clin Cancer Res. 2007;13: $5549 \mathrm{~s}-5555 \mathrm{~s}$ 
95. McKian KP, Haluska P. Cixutumumab. Expert Opin Investig Drugs. 2009; 18:1025-1033.

96. Weickhardt A, Doebele R, Oton A, et al. A phase I/II study of erlotinib in combination with the anti-insulin-like growth factor-1 receptor monoclonal antibody IMC-A12 (cixutumumab) in patients with advanced non-small cell lung cancer. $J$ Thorac Oncol. 2012;7:419-426.

97. Scagliotti GV, Novello S. The role of the insulin-like growth factor signaling pathway in non-small cell lung cancer and other solid tumors. Cancer Treat Rev. 2012;38:292-302.

98. Karp DD, Paz-Ares LG, Novello S, et al. Phase II study of the antiinsulin-like growth factor type 1 receptor antibody CP-751,871 in combination with paclitaxel and carboplatin in previously untreated, locally advanced, or metastatic non-small-cell lung cancer. $J$ Clin Oncol. 2009;27:2516-2522.

99. Gualberto A, Hixon ML, Karp DD, et al. Pre-treatment levels of circulating free IGF-1 identify NSCLC patients who derive clinical benefit from figitumumab. Br J Cancer. 2011;104:68-74.

100. Krysan K, Merchant FH, Zhu L, et al. COX-2-dependent stabilization of survivin in non-small cell lung cancer. FASEB J. 2004;18:206-208.

101. Li F, Liu Y, Chen H, et al. EGFR and COX-2 protein expression in non-small cell lung cancer and the correlation with clinical features. J Exp Clin Cancer Res. 2011;30:27.

102. Tennis MA, Vanscoyk M, Keith RL, Winn RA. The role of prostacyclin in lung cancer. Transl Res. 2010;155:57-61.

103. Mutter R, Lu B, Carbone DP, et al. A phase II study of celecoxib in combination with paclitaxel, carboplatin, and radiotherapy for patients with inoperable stage IIIA/B non-small cell lung cancer. Clin Cancer Res. 2009;15:2158-2165.

104. Mao JT, Roth MD, Fishbein MC, et al. Lung cancer chemoprevention with celecoxib in former smokers. Cancer Prev Res (Phila). 2011;4: 984-993.

105. Cathcart MC, Gray SG, Baird AM, et al. Prostacyclin synthase expression and epigenetic regulation in nonsmall cell lung cancer. Cancer. 2011;117:5121-5132.

106. Keith RL, Karoor V, Mozer AB, Hudish TM, Le M, Miller YE. Chemoprevention of murine lung cancer by gefitinib in combination with prostacyclin synthase overexpression. Lung Cancer. 2010;70: $37-42$.

107. Keith RL, Miller YE, Hoshikawa Y, et al. Manipulation of pulmonary prostacyclin synthase expression prevents murine lung cancer. Cancer Res. 2002;62:734-740.

108. Nemenoff R, Meyer AM, Hudish TM, et al. Prostacyclin prevents murine lung cancer independent of the membrane receptor by activation of peroxisomal proliferator - activated receptor gamma. Cancer Prev Res (Phila). 2008;1:349-356.

109. Hazra S, Peebles KA, Sharma S, Mao JT, Dubinett SM. The role of PPARgamma in the cyclooxygenase pathway in lung cancer. PPAR Res. 2008;2008:790568.

110. Sasaki H, Tanahashi M, Yukiue H, et al. Decreased perioxisome proliferator-activated receptor gamma gene expression was correlated with poor prognosis in patients with lung cancer. Lung Cancer. 2002;36:71-76.

111. Govindarajan R, Ratnasinghe L, Simmons DL, et al. Thiazolidinediones and the risk of lung, prostate, and colon cancer in patients with diabetes. J Clin Oncol. 2007;25:1476-1481.

112. Wang M, Zhao J, Zhang LM, et al. Combined erlotinib and cetuximab overcome the acquired resistance to epidermal growth factor receptors tyrosine kinase inhibitor in non-small-cell lung cancer. J Cancer Res Clin Oncol. 2012;138:2069-2077.

113. Haura EB, Tanvetyanon T, Chiappori A, et al. Phase I/II study of the Src inhibitor dasatinib in combination with erlotinib in advanced non-small-cell lung cancer. J Clin Oncol. 2010;28:1387-1394.
114. Yamamoto N, Murakami H, Takahashi T, et al. Final results of a Japanese phase 1 trial evaluating a c-met inhibitor tivantinib in combination with an EGFR inhibitor erlotinib in advanced/metastatic non-small cell lung cancer (ARQ 197-003/005 study). Ann Oncol. 2012;23 Suppl 9:ix424.

115. Gridelli C, Morgillo F, Favaretto A, et al. Sorafenib in combination with erlotinib or with gemcitabine in elderly patients with advanced non-small-cell lung cancer: a randomized phase II study. Ann Oncol. 2011;22:1528-1534.

116. Scagliotti GV, Krzakowski M, Szczesna A, et al. Sunitinib plus erlotinib versus placebo plus erlotinib in patients with previously treated advanced non-small-cell lung cancer: a phase III trial. J Clin Oncol. 2012;30:2070-2078.

117. Van Scoyk M, Randall J, Sergew A, Williams LM, Tennis M, Winn RA. Wnt signaling pathway and lung disease. Transl Res. 2008;151:175-180.

118. Tennis M, Van Scoyk M, Winn RA. Role of the wnt signaling pathway and lung cancer. J Thorac Oncol. 2007;2:889-892.

119. Pacheco-Pinedo EC, Durham AC, Stewart KM, et al. Wnt/ $\beta$-catenin signaling accelerates mouse lung tumorigenesis by imposing an embryonic distal progenitor phenotype on lung epithelium. $J$ Clin Invest. 2011;121:1935-1945.

120. Kim J, You L, Xu Z, et al. Wnt inhibitory factor inhibits lung cancer cell growth. J Thorac Cardiovasc Surg. 2007;133:733-737.

121. Yao H, Ashihara E, Strovel JW, et al. AV-65, a novel Wnt/beta-catenin signal inhibitor, successfully suppresses progression of multiple myeloma in a mouse model. Blood Cancer J. 2011;1:e43.

122. Winn RA, Marek L, Han SY, et al. Restoration of Wnt-7a expression reverses non-small cell lung cancer cellular transformation through frizzled-9-mediated growth inhibition and promotion of cell differentiation. J Biol Chem. 2005;280:19625-19634.

123. Tennis MA, Van Scoyk MM, Freeman SV, Vandervest KM, Nemenoff RA, Winn RA. Sprouty-4 inhibits transformed cell growth, migration and invasion, and epithelial-mesenchymal transition, and is regulated by Wnt7A through PPARgamma in non-small cell lung cancer. Mol Cancer Res. 2010;8:833-843.

124. Tennis MA, Vanscoyk MM, Wilson LA, Kelley N, Winn RA. Methylation of Wnt7a is modulated by DNMT1 and cigarette smoke condensate in non-small cell lung cancer. PLoS One. 2012;7:e32921.

125. Kaukinen S, Ylitalo P, Pessi T, Vapaatalo H. Hemodynamic effects of iloprost, a prostacyclin analog. Clin Pharmacol Ther. 1984; 36:464-469.

126. Tennis MA, Van Scoyk M, Heasley LE, et al. Prostacyclin inhibits non-small cell lung cancer growth by a frizzled 9-dependent pathway that is blocked by secreted frizzled-related protein 1. Neoplasia. 2010;12:244-253.

127. Zhang S, Zhang H, Yang X, et al. Detection of EGFR and KRAS somatic mutations in tumor tissue and peripheral blood by a liquidchip technology for patients with advanced non-small cell lung cancer. J Clin Oncol. 2012;30 Suppl:e18142.

128. Wang K, Stephens P, Yelensky R, et al. Frequency of actionable genomic alterations in early-stage lung adenocarcinoma (LA) detected by next-generation sequencing (NGS). J Clin Oncol. 2012; 30 Suppl:e17541.

129. Peifer M, Fernández-Cuesta L, Sos ML, et al. Integrative genome analyses identify key somatic driver mutations of small-cell lung cancer. Nat Genet. 2012;44:1104-1110.

130. Rudin CM, Durinck S, Stawiski EW, et al. Comprehensive genomic analysis identifies SOX2 as a frequently amplified gene in small-cell lung cancer. Nat Genet. 2012;44:1111-1116.

131. Cancer Genome Atlas Research Network. Comprehensive genomic characterization of squamous cell lung cancers. Nature. 2012;489:519-525. 


\section{Publish your work in this journal}

Pharmacogenomics and Personalized Medicine is an international, peerreviewed, open access journal characterizing the influence of genotype on pharmacology leading to the development of personalized treatment programs and individualized drug selection for improved safety, efficacy and sustainability. This journal is indexed on the American Chemical
Society's Chemical Abstracts Service (CAS). The manuscript management system is completely online and includes a very quick and fair peer-review system, which is all easy to use. Visit http://www.dovepress. com/testimonials.php to read real quotes from published authors.

Submit your manuscript here: http://www.dovepress.com/pharmacogenomics-and-personalized-medicine-journal 